\title{
MONITORING WATER HYACINTH IN KUTTANAD, INDIA USING SENTINEL-1 SAR DATA
}

\author{
Morgan Simpson ${ }^{1}$, Armando Marino ${ }^{1}$, G. Nagendra Prabhu ${ }^{2}$, Deepayan Bhowmik ${ }^{1}$, \\ Srikanth Rupavatharam ${ }^{3}$, Aviraj Datta ${ }^{3}$, Adam Kleczkowski ${ }^{4}$, J. Alice R. P. Sujeetha $^{5}$, Savitri Maharaj ${ }^{1}$ \\ ${ }^{1}$ Faculty of Natural Sciences, University of Stirling, Stirling, UK \\ ${ }^{2}$ Sanatana Dharma College, Alleppey, Kerala, India \\ ${ }^{3}$ International Crops Research Institute for the Semi-Arid Tropics, Hyderabad, India \\ ${ }^{4}$ Mathematics and Statistics, University of Strathclyde, Glasgow, UK \\ ${ }^{5}$ National Institute of Plant Health Management, Hyderabad, India
}

\begin{abstract}
Water Hyacinth is an aquatic macrophyte and highly invasive species, indigenous to Amazonia, Brazil and tropical South America. It was first introduced to India in 1896 and has now become and environmental and social nuisance throughout the country in community ponds, freshwater lakes, irrigation channels, rivers and most other surface waterbodies. Considering the adverse impact the infesting weed has, a constant monitoring is needed to aid policy makers involved in remedial measures. Due to the synoptic coverage provided by satellite imaging and other remote sensing practices, it is convenient to find a solution using this type of data. This paper looks at the use of Synthetic Aperture Radar (SAR) Sentinel1 to detect water hyacinth at an early stage of its life-cycle. While SAR has been used prominently to monitor wetlands, the technique is yet to be fully exploited for monitoring water hyacinth and we seek to fill this knowledge gap. We compare different change detection methodologies based on dual polarimetric data. We also demonstrate how Sentinel-1 can be used to monitor this type of aquatic weeds in our study areas, which is Vembanad Lake in Kuttanad, Kerala.
\end{abstract}

Index Terms - Water Hyacinth, remote monitoring, RADAR, SENTINAL-1, SAR.

\section{INTRODUCTION}

This work presents the very first methodology to detect invasive aquatic weeds (in particular Water Hyacinth) in India using Sentinel-1 radar satellite data. Waterways are important for India, where they have been utilised for commodity transport, local conveyance, irrigation, drainage, flood mitigation and as drinking water source. Water Hyacinth (Eichhornia crassipes) is a highly invasive aquatic plant species, indigenous to Amazonia, Brazil and tropical South America. First introduced as an ornamental plant in 1896 in Botanical Garden, Shibpur, West Bengal, India [1], over the years it infested fresh water bodies as an invasive weed species throughout the country across various agro-climatic conditions. International

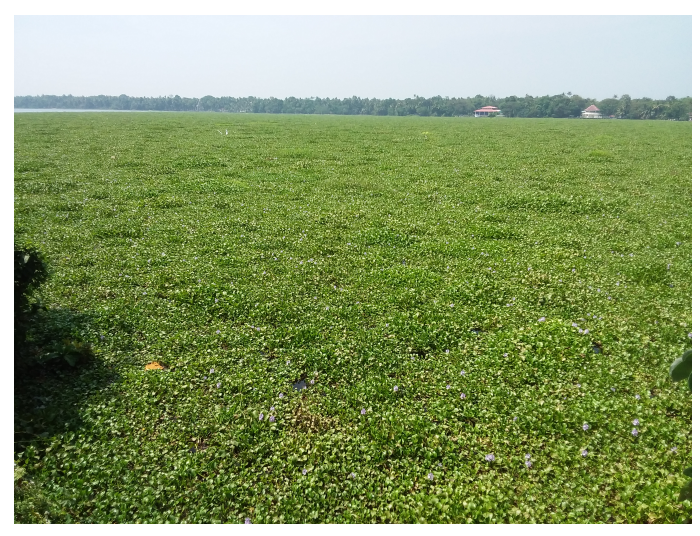

Fig. 1. Water hyacinth infestation in Thannermukkom Salt Water Barrier, India (26/01/2020). Credit: Dr. G. N. Prabhu.

Union for Conservation of Nature's (IUCN) has identified Water Hyacinth among the most dangerous invasive species in the world as it is very difficult to eliminate from a water body and has significant adverse socio-economic repercussions [2].

The weed is characterised by its rapid dispersal, growth and reproductive capabilities and the infestation has major environmental and socio-economic impact, e.g., $(i)$ depletion of dissolved oxygen in open waters reducing fish populations; (ii) damage to fishing boats adversely impacting their fuel efficiency; (iii) makes casting net difficult by covering the water surface; (iv) blockages to small channels, rivers and canals, causing transport delays; $(v)$ a reduction in water flow and power loss / damage to hydroelectric power stations, as well as blockages of irrigation channels; ( $v i)$ reduced potability of drinking water, with potential health risks; and (vii) an increase in disease vectors, such as mosquitoes. The physical removal of the weed normally involves manual removal through harvesting and in-situ cutting of the plant. The installation of surface screens or barriers to arrest the weed mat for cutting can make this process easier [3], however, physical methods are labour-intensive and suboptimal or impossible for removal within large catchment areas. 
Due to the synoptic coverage provided by satellite Everitt et al. [4] found that water hyacinth could be distinguished in colour infrared imagery across a temporal scale at multiple different study sites, with further analysis allowing the infestations to be quantified. A previous study monitoring the Gwydir Wetlands, Australia, used images captured from the optical satellite Landsat- 8 to monitor potential water hyacinth infestations within the site. The result showed a means of optical surveillance for the aquatic vegetation behaviour at a large spatial scale [5]. Cavalli et al. [6] monitored Lake Victoria, the second largest freshwater lake in the world, using Landsat, ASTER and ENVISAT. The study applied a classification algorithm to ETM+ data derived from Landsat, allowing discrimination of certain aquatic plants present within the lake. A study of aquatic plants using Quickbird multispectral data of Turkey was capable of producing an unsupervised classification accuracy of $83 \%$ when identifying and mapping plant species [7]. Mixed pixels were identified as a main limitation in the procedure.

Recently, there has been increasing use of UAVs and small drone aircraft for the monitoring of aquatic environments. A study of the Trent-Severn Waterway in Canada was conducted using high-resolution drone aerial surveys. Chabot et al. [8] used an automated classification algorithm with a supervised machine-learning classifier on a collection of radiometrically calibrated multispectral drone imagery. The classification algorithm was found to have an overall accuracy of $92 \%$ when classifying above-surface aquatic vegetation and an accuracy of $84 \%$ when classifying submerged vegetation.

However, optical data are not always available with cloud cover is a strong limitation when we want to achieve prompt alert system that is able to detect the infesting weed at early occurrences. SAR can help with this due to the capability to monitor in all-weathers, day- or night-time. The scattering processes of SAR allow mapping of marsh, surface waters and forest to be determined from volume-, double-bounce and surface scattering [9]. Hess et al. [10] used SAR to distinguish between water, herbaceous vegetation and forest within the Amazon Basin. Using a classification algorithm on SAR mosaics, a producer's accuracy of $85 \%$ was achieved when classifying wetland area, woody vegetation and aquatic macrophytes. This work is showing for the first time the possibility to use radar data to detect water hyacinth using satellite SAR with a focus on our test site in India (Fig. 1).

\section{METHODOLOGY}

\subsection{Study Area}

Kuttanad, Kerala is a paddy-rich region in south-west India. About two-thirds of the land area is covered with wetlands with an area size of about $875 \mathrm{~km}^{2}$. The department of agriculture, Government of Kerala, has reported intensive fertilisers usage by local farmers in the Kuttanad region [11]. This has resulted in an increase in water hyacinth found within the

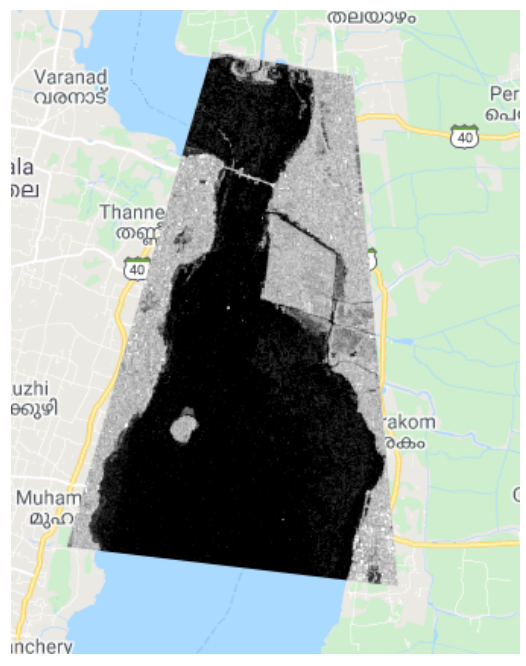

(a)

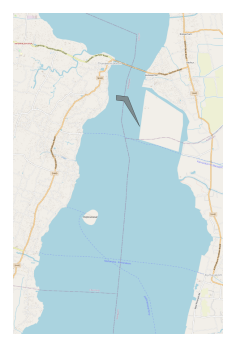

(b)

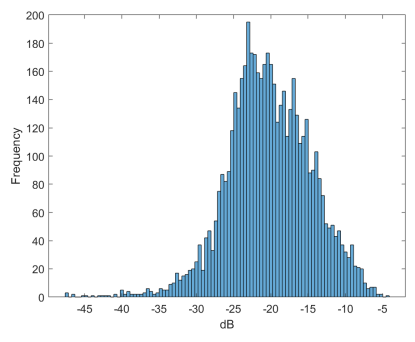

(c)
Fig. 2. Image from 02-Nov-2019 in Sentinel-1 VV Channel showing reduced water hyacinth on surface of Vembanad Lake. (a) VV intensity, (b) polygon for histogram, (c) histogram of clean water pixels. Sentinel-1 (credits: ESA).

major lakes of the region. Due to the presence of water hyacinth within the region's waterways, impacts have been felt on fisheries, drinking water, irrigation, transport and recreational use of the water bodies. This study focuses on the Vembanad Lake, the largest Ramsar site in Kerala, India. We could acquire validation data for this location by gathering photographic evidences of the infestation (Fig. 1).

\subsection{Satellite Data}

In this study we used dual-polarimetric Sentinel-1 Sar data, provided by the European Space Agency (ESA) through the Copernicus programme. The Mode of acquisition is IW GRD, this means that data are intensities using a multi-look $1 \times 4$. The special resolution is approximately $20 \times 20 \mathrm{~m}$ and using all available orbits, the temporal resolution is up to 7 days on our test site (12 days with a single orbit). Sentinel-1 images where calibrated into Normalised Radar Cross Section, georeferenced and converted into $\mathrm{dB}\left(\sigma_{d B}^{0}\right)$.

\subsection{Physical model}

Our working hypothesis is that water hyacinth infestation alters the scattering by increasing the roughness of the lake sur- 


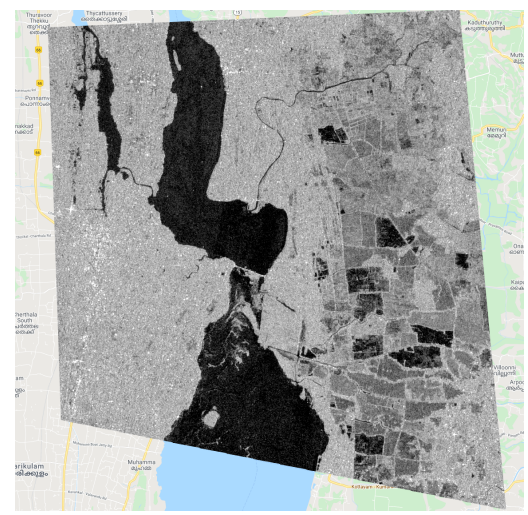

(a)

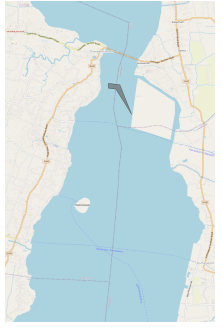

(b)

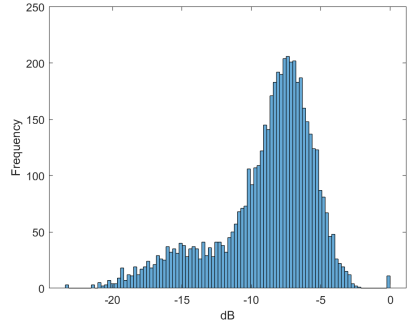

(c)
Fig. 3. Image from 19-Jan-2020 in Sentinel-1 VV Channel showing water hyacinth on surface of Vembanad Lake. (a) VV intensity, (b) poligon used for histogram, (c) histogram of pixels in the polygon (Sentinel-1, credits: ESA).

face. This should be distinguishable in the satellite image as spots or patches with high brightness. This increase in surface brightness as calm waters of a lake will scatter the most of the electromagnetic radiation in the specular direction and therefore will appear darker; but the presence non-reflective water hyacinth mat on the water surface thus will appear brighter in the image and should be picked up by the radar.

\subsection{Data Analysis}

As the first step we inspected images to check if our working hypothesis was correct. Inspecting the images for the Vembanad Lake showed that there was clearly something floating on the water surface. Regions of Interest (ROIs) were established to create time-series of VV and VH channel data. Initial viewing of the time-series data showed that there were clear dates where the VV channel data peaked and troughed. Inspection of these dates showed that, on these dates, the water surface was cleaner (Fig. 2) or more infested with water hyacinth (Fig. 3). A change detection methodology was established using the ratio of VV polarization, which is the channel where the infestation is more visible.

The change detection threshold was set on the log difference which is obtained by considering the images in $\mathrm{dB}$ values and subtracting the infested image VV values from the clean image $\mathrm{VV}$ values. The threshold was then set using the

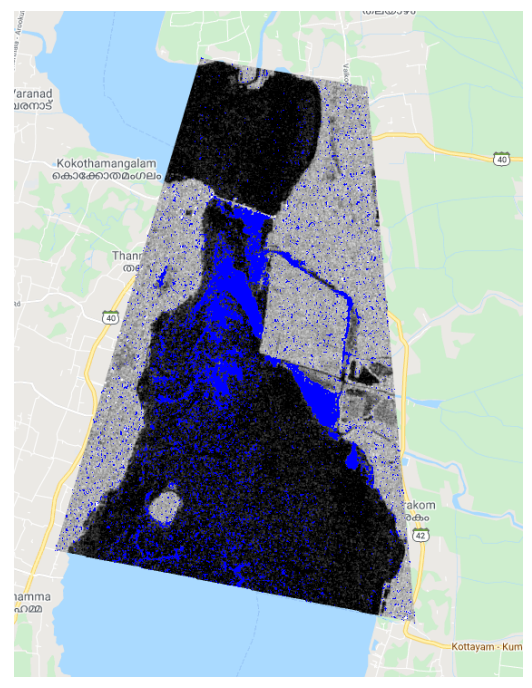

Fig. 4. Detection mask using the ratio of VV channel intensities. Images compared: 19-Jan-2020 and 02-Nov-2019. Threshold set using the histograms. Sentinel-1 credits: ESA.

histogram that shows that $3 \mathrm{~dB}$ is a good value to separate infested and clean pixels. Using the histogram we minimise the probability of false alarms while at the same time maximizing the probability of detection.

\section{RESULTS AND DISCUSSIONS}

Within the scope of this paper we present results for a single infested area with the intention to extend the study in further test sites and demonstrate the effectiveness of our hypothesis. Figure 3 shows a picture of one of the infested areas in the lake. The picture was taken on the 27 th of January. The VV intensity channel is presented in Fig. 3.(a). The date for this acquisition is the 19th of January 2020 which was the closest match with the photo. The area depicted in the photo is near the north barrage of the lake also indicated by a polygon in Fig. 3.(b).

The histogram of the area is presented in Fig. 3.(c) where it is clear the bimodal nature of the area where pixels of clean water are mixed with pixels with infestation. As a comparison in Fig. 2 we have a date, the 2nd of November 2019 when the infestation was much lower. The histogram show that the intensity of pixels is clearly lower. Using the two histograms we could set a threshold and produce the detection mask in Fig. 4. It is interesting to see how we can detect the presence of the weed using this simple change detector.

We also investigate the potential of statistical parametric approaches for the change detection by fitting Gaussian probability distribution functions (PDF) on the histograms. The Gaussian models can be expressed as

$$
f(x)=\sum_{i=1}^{n} a_{i} e^{\left[\left(\frac{x-b_{i}}{c_{i}}\right)^{2}\right]},
$$



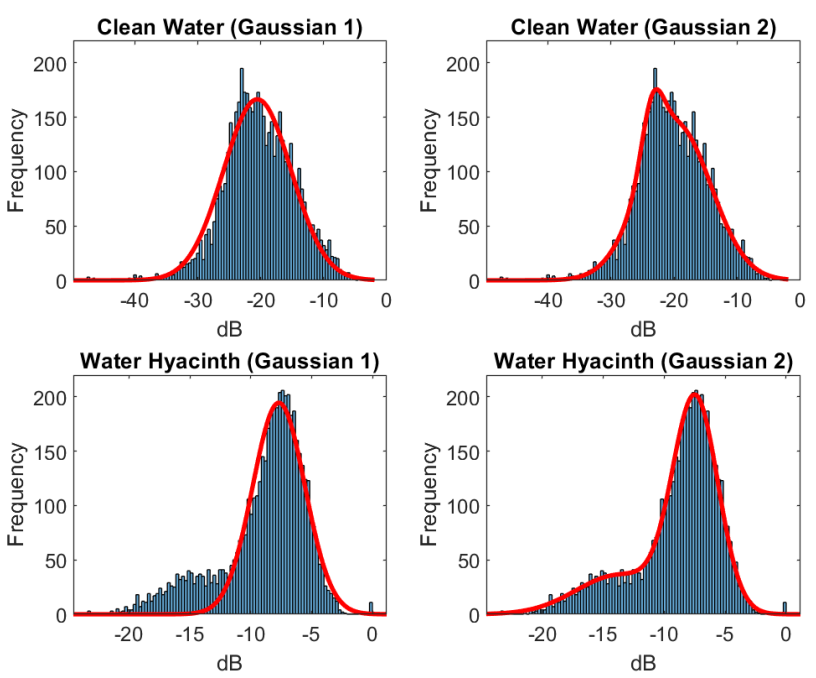

Fig. 5. Parametric Gaussian model fit to the histograms. Row 1 and row 2 are for clean and infested water, respectively. Column 1 and column 2 show comparisons for single $(n=1)$ and two $(n=2)$ peaks Gaussian distributions fits.

where, $f(x)$ is the distribution for input data $x, n$ is the number of peaks and $a, b$ and $c$ are the amplitude, centroid and width parameters, respectively.

We estimated the Gaussian model parameters by fitting the PDFs on the histograms of the clean and infested areas and the results are shown in Fig. 5. Our study indicates good parametric fit when $n=2$, i.e., mixture of two Gaussian distributions particularly for water hyacinth infested area. This is due to the heterogeneous nature (weed and water both) of the region of interest. On contrary, the homogeneous nature of clean water can be well approximated by a single peak distribution. The model parameters, $a, b$ and $c$ shows clear distinction between clean and infested areas and hence can be used for change detection either using a simple thresholding method or an advance machine learning based approach.

\section{CONCLUSIONS}

While there is an established background for the practice of remote sensing in the detection of water hyacinth, the use Synthetic Aperture Radar (SAR) is yet to be fully exploited in the detection of invasive plant species. Using Sentinel-1 data of Vembanad Lake, India, we demonstrated how SAR can be used to monitor water hyacinth. Pixels values have been extracted from regions of interest within the lake and show that backscattering intensities differ between clean sites and infested sites. From this, basic detection masks have been established to begin detecting the presence of water hyacinth within Vembanad Lake. In future, more sophisticated algorithms (statistical parametric approaches) will be developed.

Acknowledgement: This work was funded by a UK RAEng GCRF grant (FF/1920/1/37).

\section{REFERENCES}

[1] V. Naidu, A. Deriya, S. Naik, S. Paroha, and P. Khankhane, "Water use efficiency and phytoremediation potential of water hyacinth under elevated CO2," Indian Journal of Weed Science, vol. 46, no. 3, pp. 274-277, 2014.

[2] T. Téllez, E. López, G. Granado, E. Pérez, R. López, and J. Guzmán, "The water hyacinth, Eichhornia crassipes: an invasive plant in the Guadiana River Basin (Spain)," Aquatic Invasions, vol. 3, no. 1, pp. 42-53, 2008.

[3] U. Uka, K. Chukwuka, and F. Daddy, "Water hyacinth infestation and management in nigeria inland waters: a review," Plant Sci, vol. 2, pp. 480-488, 2007.

[4] J. Everitt, C. Yang, D. Escobar, C. Webster, R. Lonard, and M. Davis, "Using remote sensing and spatial information technologies to detect and map two aquatic macrophytes," Journal of Aquatic Plant Management, vol. 37, pp. 71-80, 1999.

[5] R. Shilpakar, J. Li, L. Ge, P. Dawson, and S. Chapman, "Water hyacinth mapping in gwydir wetlands using remote sensing techniques," in NSW Biennial Weeds Conference, 2017, pp. 87-91.

[6] R. Cavalli, G. Laneve, L. Fusilli, S. Pignatti, and F. Santini, "Remote sensing water observation for supporting lake victoria weed management," J. of environmental management, vol. 90, no. 7, pp. 2199-2211, 2009.

[7] O. Dogan, Z. Akyurek, and M. Beklioglu, "Identification and mapping of submerged plants in a shallow lake using quickbird satellite data," Journal of environmental management, vol. 90, no. 7, pp. 2138-2143, 2009.

[8] D. Chabot, C. Dillon, A. Shemrock, N. Weissflog, and E. P. Sager, "An object-based image analysis workflow for monitoring shallow-water aquatic vegetation in multispectral drone imagery," ISPRS International Journal of Geo-Information, vol. 7, no. 8, p. 294, 2018.

[9] B. Brisco, "Mapping and monitoring surface water and wetlands with synthetic aperture radar," Remote Sensing of Wetlands: Applications and Adv., pp. 119-136, 2015.

[10] L. Hess, J. Melack, A. Affonso, C. Barbosa, M. GastilBuhl, and E. Novo, "Wetlands of the lowland amazon basin: Extent, vegetative cover, and dual-season inundated area as mapped with JERS-1 synthetic aperture radar," Wetlands, vol. 35, no. 4, pp. 745-756, 2015.

[11] M. Kumari, S. Syamaprasad, and S. Das, "Inland waterway as an alternative and sustainable transport in kuttanad region of kerala, india," in Adv. in Water Resources Engineering and Management, 2020, pp. 245-257. 